\title{
Nanospheres caped Pt(II) and Pt (IV): synthesis and evaluation as anti- microbial and Antifungal Agent
}

\author{
Hatice Öğ̈̈tçü ${ }^{1}$, Nurdan K. Yetim², 3, Elvan H. Özkan ${ }^{3}$, Orçun Eren $^{3}$, Gamze Kaya ${ }^{3}$, Nurşen Sarı ${ }^{3 *}$, \\ Ali Dişli ${ }^{3}$
}

${ }^{1}$ Ahi Evran University, Faculty of Arts and Science, Department of Biology, Kirşehir, Türkiye

${ }^{2}$ Kırklareli University, Faculty of Arts and Science, Department of Chemistry, Kırklareli, Turkiye

${ }^{3}$ Gazi University, Faculty of Science, Department of Chemistry, Ankara, 06500, Turkiye

"Corresponding author: e-mail: nursens@gazi.edu.tr

\begin{abstract}
Antimicrobial and antifungal polymers are gaining the attention of pharmaceutical makers and industrial design. Nanospheres-Polymers attached Platinum(II) / (IV) complexes have been synthesized to investigate antimicrobial activities. Firstly, nanospheres involving Schiff bases were synthesized from (aminomethyl) polystyrene and four substitute salicylaldehyde (2-hydroxy benzaldehyde, 5-fluoro-2-hydroxy benzaldehyde, 5-kloro-2-hydroxy benzaldehyde, 5-bromo-2-hydroxy benzaldehyde). Secondly, polymers attached Platinum(II) / (IV) complexes have been prepared by means of template method. The IR spectra show that the ligands act in a monovalent bidentate fashion all nanospheres involving Schiff bases. Square-planar and octahedral structures are proposed for $\mathrm{Pt}(\mathrm{II})$ and $\mathrm{Pt}(\mathrm{IV})$, respectively. All these substances have been examined for antibacterial activity against pathogenic strains, and antifungal activity. In particular, Pt(IV) complexes were more potent bactericides than all of the synthesized substances.
\end{abstract}

Keywords: antimicrobial agent, antifungal agent, poly(styrene), caped platinium.

\section{INTRODUCTION}

The appropriate polymers have been designed and used for the drug delivery technology. Especially, biodegradable polymers are important for drug delivery. Over the past few decades, polymeric-materials with bioactive agents have been preferred in the pharmaceutical industry $^{1}$. Materials have nanoscale formats from polymeric-materials is important for drug delivery technology. The efficiency of drug delivery to various parts of the body is directly affected by particle size ${ }^{2}$. Nanoscale drug carriers are helping to efficient drug distribution. Kohli and $\mathrm{Alpar}^{3}$ have noted that the efficiency of delivery into gastrointestinal absorption is achieved for the particle diameter of $100 \mathrm{~nm}$. Advantages of nanostructure-mediated drug delivery include the ability to deliver drug molecules directly into cells.

Platinum is an essential trace element in the anti-cancer research. So, numerous derivatives of $\mathrm{Pt}(\mathrm{II}) /$ $\mathrm{Pt}(\mathrm{IV})$-complexes have been prepared in recent years ${ }^{4-7}$. Since 2000, increased research on Platinum-complexes linked with polyamine ligands ${ }^{8-10}$. The amine groups of the polyamine linkers are groups capable of hydrogen bond formation with DNA atoms such as the O6 of guanine or the $\mathrm{O} 3$ of thymine ${ }^{11}$. According to literature, the first study on Platinum-nanoparticles with the linear polymer has been reported by Ahmadi et al. in $1996^{12}$. And then, Pt nanowires were synthesized by Fenske et al. using dodecyl amine as ligands ${ }^{\mathbf{1 3}}$. Hence, the synthesis of Pt-nanostructure has been intensively reported on cytotoxicity, genotoxicity and protein expression ${ }^{14,15}$.

Antimicrobial polymers have the advantage that they are chemically stable and do not permeate through the skin. Furthermore, they play an important role in reducing the incidences of infections caused by biomaterial implant. As far as we know, no studies have been carried out on nanosphere including Platinium-Schiff bases complexes. This study aimed to fill in this gap. Novel Platinum-Schiff bases derivatives were investigated to find out the antibacterial properties of Schiff bases and their $\mathrm{Pt}(\mathrm{II}) / \mathrm{Pt}(\mathrm{IV})$ complexes.

\section{MATERIAL AND METHODS}

\section{Materials and physical measurements}

All other materials were reagent grade (Sigma-Aldrich Company). ${ }^{1} \mathrm{H}-\mathrm{NMR}$ spectra of the modified polymers were recorded with a Bruker Spectrospin Avance DPX400 instrument using TMS as internal standard and DMSO- $\mathrm{d}_{6}$ as the solvent. Elemental analyses were carried out with an LECO, CHNS-932 instrument. Metal contents were determined by using a Philips PU 9285 atomic absorption instrument at Tübitak, Ankara, Turkey. IR spectra were recorded on a Mattson-5000 FT-IR instrument in $\mathrm{KBr}$ pellets. Scanning electron microscopy of the Au-Pd-coated compounds was done by using a JEOL JEM 100 CX II scanning electron microscope (JEOL, Peabody, MA) equipped with a Link analytical system. The electron energy used was $20 \mathrm{keV}$.

\section{STUDIES ON SYNTHESIS}

Synthesis of nanospheres capped Schiff Bases (APS-SchX, $\mathrm{X}$ : -F, -Cl, -Br)

The nanospheres capped-Schiff bases (APS-SchX) were prepared by reacting of (aminomethyl) polystyrene (APS) $(1 \mathrm{~g}, 50-100$ mesh (or $0.15-0.1 \mathrm{~nm}), 2.0 \mathrm{mmol} / \mathrm{g}-\mathrm{NH}_{2}$ loaded, $1 \%$ cross-linked (Sigma-Aldrich) in hot DMF $(15 \mathrm{~mL})$ with 2-hydroxybenzaldehydes and its derivatives (5-fluoro-2-hydroxy benzaldehyde, 5-chloro-2-hydroxy benzaldehyde and 5-bromo-2-hydroxy benzaldehyde) in DMF (10 mL) (Fig. 1A). 2-hydroxybenzaldehydes and its derivatives were added dropwise to (aminomethyl) polystyrene solution while stirring for $30 \mathrm{~min}$. This reaction mixture was stirred under reflux condenser $c a .3 \mathrm{~h}$, at $70^{\circ} \mathrm{C}$. After the mixture cooling to room temperature, nanospheres were poured into the acetone. The result- 
ing nanospheres were filtered and dried in the oven and kept with desiccator over anhydrous $\mathrm{CaCl}_{2}$.

\section{Synthesis of Polymer capped Pt(II) / Pt(IV) (APS-SchX-M)}

Polymer Attached Pt(II) / Pt(IV) complexes were synthesized by applying the same method. The polymeric-Schiff bases (APS-SchX) were prepared by reacting of (aminomethyl) polystyrene (APS) (1 g, 50-100 mesh (or $0.15-0.1 \mathrm{~nm}), 2.0 \mathrm{mmol} / \mathrm{g}-\mathrm{NH}_{2}$ loaded $1 \%$ cross-linked (Sigma-Aldrich) in hot DMF $(15 \mathrm{~mL})$ with 2-hydroxybenzaldehydes and it's derivatives 5-fluoro-2-hydroxy benzaldehyde, 5-chloro-2-hydroxy benzaldehyde and 5-bromo-2-hydroxy benzaldehyde) in DMF (10 mL). Then, a solution was stirred for $2 h$ under a reflux condenser at $50^{\circ} \mathrm{C}$. Platinium salts $\left(1.0 \mathrm{mmol} \mathrm{PtCl}_{2} /\right.$ $\left.\mathrm{PtCl}_{4}\right)$ in DMF $(5 \mathrm{~mL})$ were added to upon the mixture through $30 \mathrm{~min}$ and mixing process was continued $4 \mathrm{~h}$. Thus nanosphere polymeric-Pt(II) / Pt(IV) complexes were obtained (Fig. 1). After the mixture cooling to room temperature, nanosphere attached $\mathrm{Pt}(\mathrm{II}) / \mathrm{Pt}(\mathrm{IV})$ complexes were poured into the acetone and washed by adding acetone. The products (brown /dark brown) were filtered then dried.

\section{Detection of antimicrobial and antifungal activity}

Antifungal activities of polymer attached Schiff bases and their $\mathrm{Pt}(\mathrm{II}) / \mathrm{Pt}(\mathrm{IV})$ complexes were checked against two fungal strains such as Aspergillus fumigatus ( $A$. fumigatus), and Candida albicans (C. albicans). For the bacterial subcultures, Listeria monocytogenes (L. monocytogenes) $4 b$ ATCC19115, Staphylococcus aureus ( $S$. aureus) ATCC25923, Escherichia coli (E. coli) ATCC1230,
Salmonella typhi (S. typhi) H NCTC-901.8394, Brucella abortus (B. abortus) RSKK03026, Staphylococcus epidermis (S. epidermis sp.), Micrococcus luteus (M. luteus) ATCC 9341, Shigella dysenteriae type (S. dysenteria type) 10 NCTC 9351 and Bacillus cereus (B. cereus sp.), were chosen. For activities measurement, the media used were Mueller-Hinton agar for bacteria and Potato Dextrose agar for the fungi. Fifteen milliliters of the molten agar $\left(45^{\circ} \mathrm{C}\right)$ was aseptically mixed with either $100 \mu$ l of a bacterial suspension $\left(10^{6} \mathrm{CFU} / \mathrm{ml}\right)$ or $1 \mathrm{ml}$ fungal suspension $\left(10^{6} \mathrm{CFU} / \mathrm{ml}\right)$ and poured into $100 \mathrm{~mm} \times 15 \mathrm{~mm}$ sterile Petri dishes and allowed to solidity. Once the agar was hardened, $6 \mathrm{~mm}$ wells were bored using a sterile cork borer and entirely filled with the test solutions. And then the plates were incubated for $24 h$ at $37^{\circ} \mathrm{C}$ for bacteria and $72 h$ at room temperature for the fungi. At the end of the incubation period, the diameter of the zone of inhibition around the wells was measured.

\section{RESULTS AND DISCUSSION}

The analytical data for the ligand and its complexes together with some physical properties are summarized in Table 1. The elemental analyses can be considered compatible with the chemical formulas of the compounds due to polymers of different chain lengths ${ }^{\mathbf{1 6}}$. The weight average molecular weight $(\mathrm{Mw})$ and was suggested from element analyses. Molecular weight and molecular weight distribution ( $\mathrm{Mw} / \mathrm{Mn}$ ) were determined by GPC (Gel permeation chromatography). According to GPC, modified polymers have a very narrow molecular weight distribution (PDI, polydispersity index): 1.09, 1.15, 1.30, $1.08,1.89,1.80,1.10,1.74,2.10,2.20,2.20$ and 2.10 for

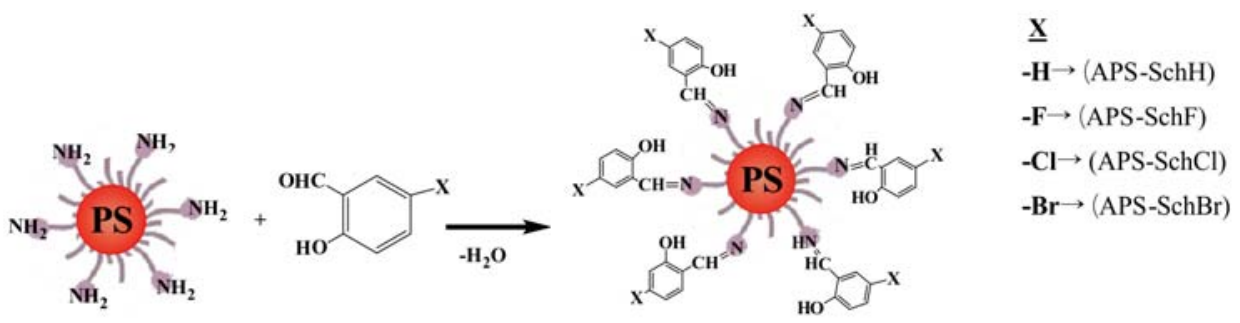

[A]
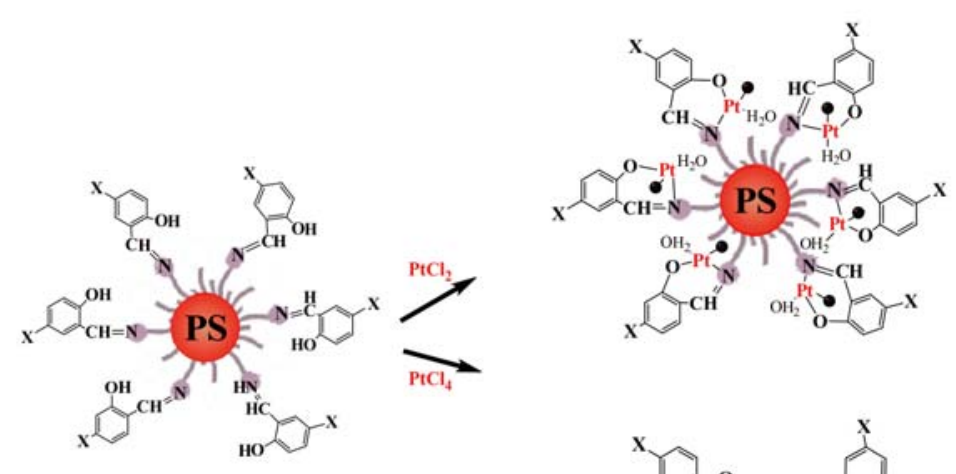

$\underline{\mathbf{x}}$

$-\mathrm{H} \rightarrow\left(\right.$ APS-SchH-Pt $\left.{ }^{2+}\right)$

$-\mathrm{F} \rightarrow\left(\right.$ APS-SchF- $\left.-\mathrm{Pt}^{2+}\right)$

$-\mathrm{Cl} \rightarrow\left(\right.$ APS-SchCl-Pt $\left.{ }^{2+}\right)$

$-\mathrm{Br} \rightarrow\left(\mathrm{APS}-\mathrm{SchBr}-\mathrm{Pt}^{2+}\right)$

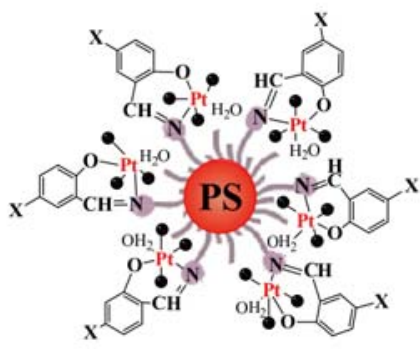

$\rightarrow \mathrm{Cl}$

$-\mathrm{H} \rightarrow\left(\right.$ APS-SchH-Pt $\left.{ }^{4+}\right)$

$-\mathrm{F} \rightarrow\left(\right.$ APS-SchF-Pt $\left.{ }^{4}\right)$

$-\mathrm{Cl} \rightarrow\left(\right.$ APS-SchCl-Pt $\left.{ }^{4+}\right)$

$-\mathrm{Br} \rightarrow\left(\mathrm{APS}-\mathrm{SchBr}-\mathrm{Pt}^{4+}\right)$

[B]

Figure 1. Synthesis rotation of Polymer attached Schiff bases [A] and $\mathrm{Pt}(\mathrm{II}) / \mathrm{Pt}(\mathrm{IV})$ [B] 
Table 1. Analytical and physical data for Polymer attached Schiff bases and Pt(II) / Pt(IV) complexes

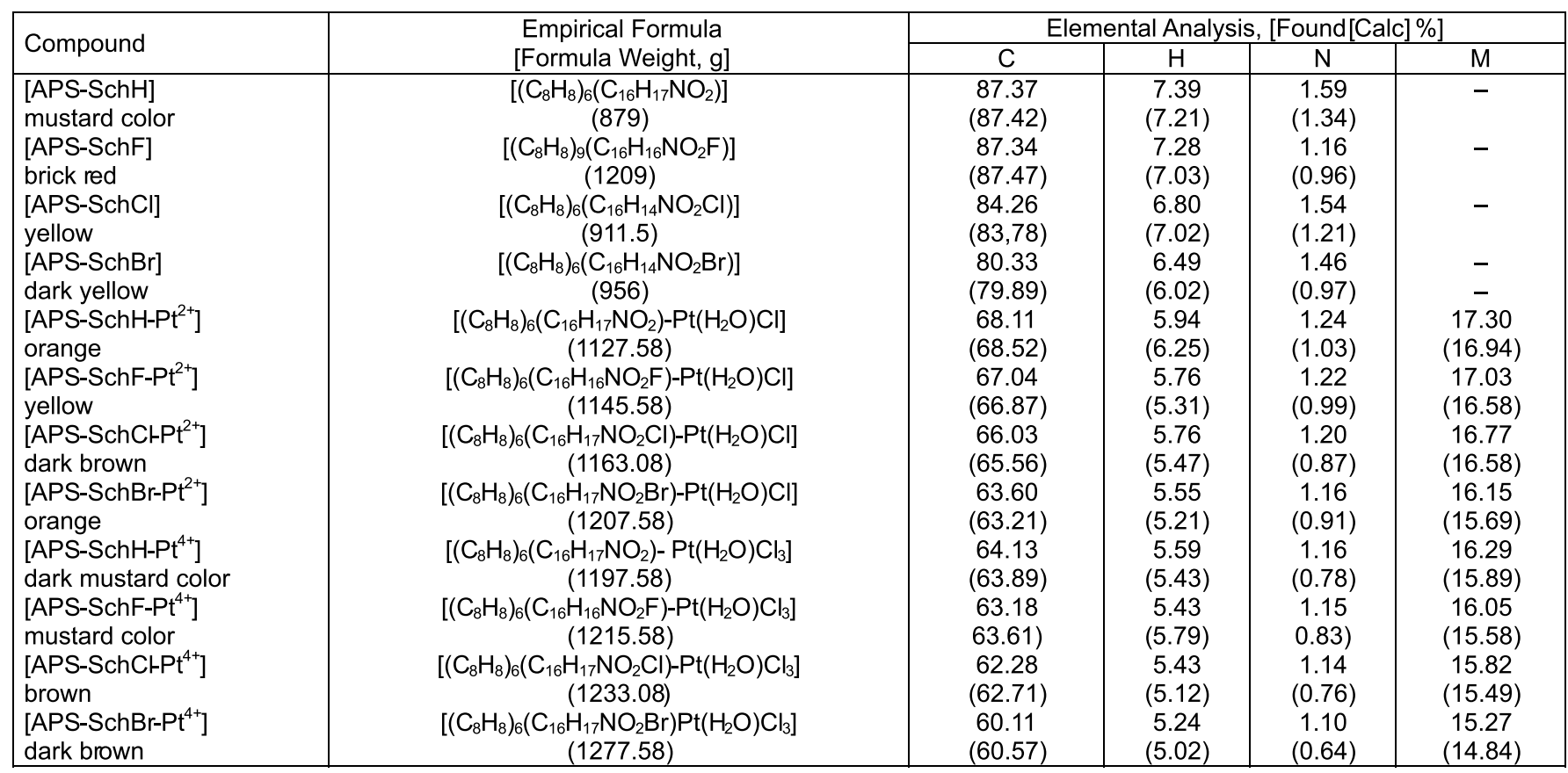

(APS-SchH), (APS-SchF), (APS-SchCl), (APS-SchBr), $\left[\mathrm{APS}-\mathrm{SchH}-\mathrm{Pt}^{2+}\right],\left[\mathrm{APS}-\mathrm{SchF}-\mathrm{Pt}^{2+}\right],\left[\mathrm{APS}-\mathrm{SchCl}-\mathrm{Pt}^{2+}\right.$, $\left[\mathrm{APS}-\mathrm{SchBr}-\mathrm{Pt}^{2+}\right],\left[\mathrm{APS}-\mathrm{SchH}-\mathrm{Pt}^{4+}\right],\left[\mathrm{APS}-\mathrm{SchF}-\mathrm{Pt}^{4+}\right]$, $\left[\mathrm{APS}-\mathrm{SchCl}-\mathrm{Pt}^{4+}\right]$ and $\left[\mathrm{APS}-\mathrm{SchBr}-\mathrm{Pt}^{4+}\right]$; respectively.

\section{IR Spectra of Polymer-Bound Azomethine and their} $\operatorname{Pt}($ II) and Pt(IV) Complexes

The characteristic peaks of IR spectra of all modified polymers including Schiff bases are given in Table 2. As in our previous studies, in the present study, three overtone peaks showed in 1941, 1872, $1798 \mathrm{~cm}^{-1}$ all of the modified polymers. For modified polymer, the vibrations of azomethine are observed between 1618 and $1621 \mathrm{~cm}^{-1}{ }^{17}$.

In the spectra of modified a polymers (APS-SchH-Pt ${ }^{2+}$ ), $\left(\right.$ APS-SchF-Pt $\left.{ }^{2+}\right),\left(\right.$ APS-SchCl-Pt $\left.{ }^{2+}\right),\left(\right.$ APS-SchBr-Pt ${ }^{2+}$ ) appearing new bands at 1625, 1628, 1624 and $1627 \mathrm{~cm}^{-1}$,
(APS-SchH-Pt $\left.{ }^{4+}\right),\left(\right.$ APS-SchF-Pt $\left.{ }^{4+}\right),\left(\right.$ APS-SchCl-Pt $\left.{ }^{4+}\right)$, (APS-SchBr-Pt ${ }^{4+}$ ) appearing bands at 1628, 1627, 1623, $1625 \mathrm{~cm}^{-1}$ respectively are assigned to $v(\mathrm{CH}=\mathrm{N})_{\text {imine group }}$ stretching vibrations. This situation was evaluated as participation Platinum atom to the polymer (Fig. 2) ${ }^{\mathbf{1 8}}$. As distinct from polymers including Schiff bases, new weak bands emerged at 427-438 and $490-520 \mathrm{~cm}^{-1}$ due to coordination of Platinum atoms with $\mathrm{N}$ and $\mathrm{O}$ atoms ${ }^{\mathbf{1 9}}$.

The IR spectra of all coordination polymer including $\mathrm{Pt}(\mathrm{II})$ and $\mathrm{Pt}(\mathrm{IV})$ atoms exhibit characteristic bands of coordination water at $c a$. 3350, 840 (weak) and 770 (weak) $\mathrm{cm}^{-1}$ assigned to $\mathrm{v}(\mathrm{OH}), \operatorname{or}(\mathrm{OH})$ and $\varrho_{\mathrm{W}}\left(\mathrm{OH}_{2}\right)$ vibrations, respectively (Sarı and Gürkan 2004). These observations clearly suggest that the water molecules are coordinated to the metal ion.

Table 2. Specific FT-IR and UV-GB spectra data of polymer attached Schiff bases and Pt(II) / Pt(IV) complexes (no: not observed)

\begin{tabular}{|c|c|c|c|c|}
\hline Compound & $\begin{array}{l}\mathrm{UOH} \\
\mathrm{UCH}=\mathrm{N}\end{array}$ & $\begin{array}{c}\text { Uoverton } \\
\mathrm{U} \mathrm{CH}(\text { arom)/aliph }\end{array}$ & UPt-O /Pt-N & $\begin{array}{c}\lambda_{\max } ; \sigma \rightarrow \sigma^{*}, \\
\mathrm{n} \rightarrow \pi^{*}(\mathrm{C}-\mathrm{N}), \pi \rightarrow \pi^{*}(\mathrm{C}-\mathrm{N}) \\
\mu_{\mathrm{eff}}(\mathrm{BM})\end{array}$ \\
\hline $\begin{array}{l}{[\text { APS-SchH] }} \\
{[\text { APS-SchF] }} \\
{[\text { APS-SchCl] }} \\
{[\text { APS-SchBr] }} \\
{\left[\text { APS-SchH- }-\mathrm{Pt}^{2+}\right]} \\
{\left[\text { APS-SchF-Pt }{ }^{2+}\right]} \\
{\left[\text { APS-SchCl-Ptt }{ }^{2+}\right]} \\
{\left[\text { APS-SchBr-Pt }{ }^{2+}\right]} \\
{\left[\text { APS-SchH-Pt }{ }^{4+}\right]} \\
{\left[\text { APS-SchF-Pt }{ }^{4+}\right]} \\
{\left[\text { APS-SchCl-Pt }{ }^{4+}\right]} \\
{\left[\text { APS-SchBr-Pt }{ }^{4+}\right]}\end{array}$ & $\begin{array}{l}3432 \\
1618 \\
3410 \\
1621 \\
3414 \\
1618 \\
3420 \\
1617 \\
3421 \\
1625 \\
3424 \\
1628 \\
3443 \\
1624 \\
3424 \\
1627 \\
3426 \\
1628 \\
3426 \\
1627 \\
3432 \\
1623 \\
3426 \\
1625 \\
\end{array}$ & $\begin{array}{c}1937,1868,1796 \\
3013,2920 \\
1936,1868,1795 \\
3013,2920 \\
1937,1867,1796 \\
3014,2923 \\
1937,1868,1794 \\
3013,2920 \\
1936,1867,1796 \\
3012,2921 \\
1935,1868,1796 \\
3015,2920 \\
1936,1868,1796 \\
3013,2920 \\
1937,1868,1796 \\
3013,2920 \\
1934,1866,1792 \\
3011,2924 \\
1937,1868,1796 \\
3023,2925 \\
1937,1868,1796 \\
3025,2931 \\
1937,1868,1796 \\
3018,2923\end{array}$ & $\begin{array}{c}- \\
- \\
- \\
- \\
- \\
- \\
- \\
- \\
\text { no/498 } \\
430 / 514 \\
437 / 520 \\
\text { no/519 } \\
\text { no/ 518 } \\
438 / 507\end{array}$ & $\begin{array}{c}227,306,- \\
- \\
227,320,- \\
- \\
226,327,418 \\
- \\
227,328,416 \\
- \\
227,304,423 \\
\text { Diamagnetic } \\
226,301,424 \\
\text { Diamagnetic } \\
227,301, \text { no } \\
\text { Diamagnetic } \\
225,304,427 \\
\text { Diamagnetic } \\
227,306, \text { no, } 474 \\
\text { Diamagnetic } \\
227,305,421,470 \\
\text { Diamagnetic } \\
226,307,420,475 \\
\text { Diamagnetic } \\
\text { 227, 301, no, } 476 \\
\text { Diamagnetic }\end{array}$ \\
\hline
\end{tabular}



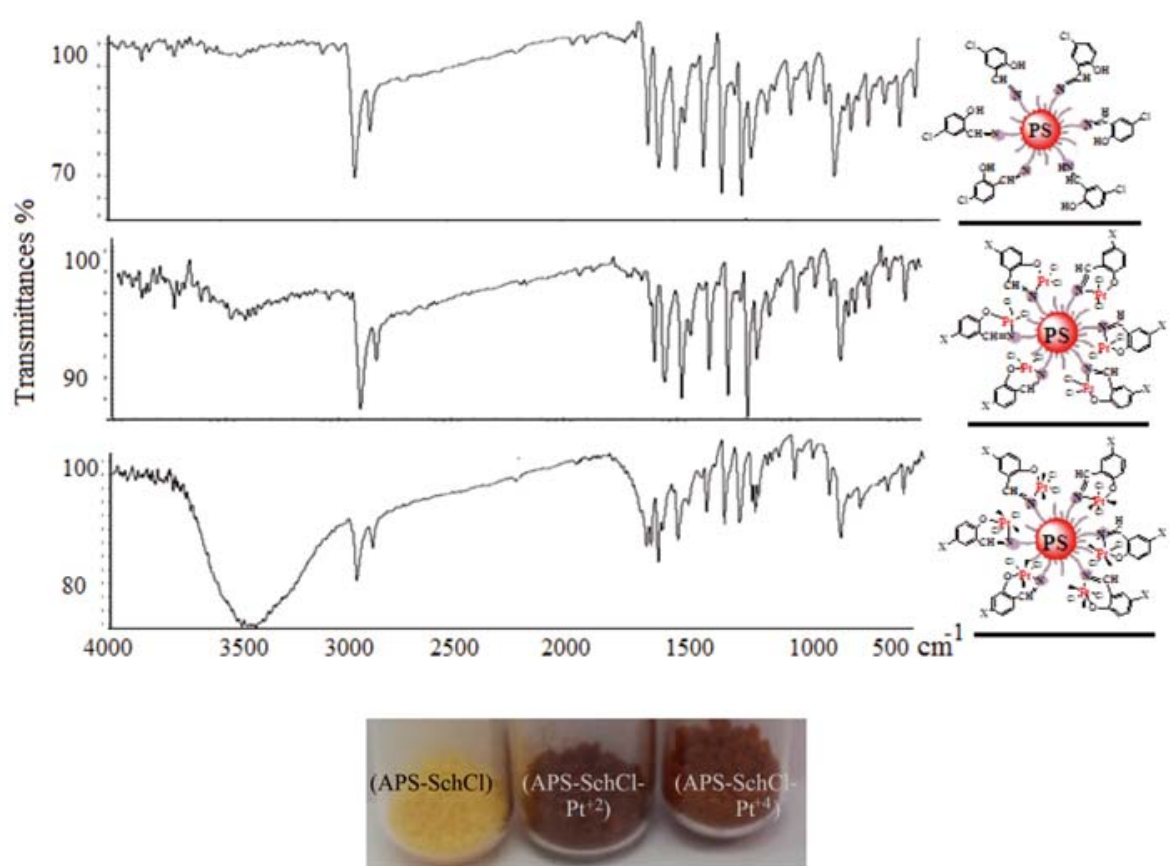

Figure 2. FT-IR spectra of (APS-SchCl) and its $\mathrm{Pt}(\mathrm{II})$ and $\mathrm{Pt}(\mathrm{IV})$ coordination polymer UV-Visible and ${ }^{1} \mathrm{H}$-NMR Spectra of Polymer-Bound
Azomethine and their $\mathrm{Pt}(\mathrm{II})$ and $\mathrm{Pt}(\mathrm{IV})$ Complexes

The ${ }^{1} \mathrm{H}$ NMR spectrum of Polymer-Bound Azomethine and their some Pt(II) Complexes, recorded in DMSO$-\mathrm{d}_{6}$ showed the following signals: aliphatic $-\mathrm{CH},-\mathrm{CH}_{2}$ and $-\mathrm{CH}_{3}$ proton of (APS-SchH), (APS-SchF), (APS-SchCl) and (APS-SchBr) at 1.10-2.90 ppm, 1.15-2.85 ppm, 1.10-2.90 ppm and 1.00-2.90 ppm, respectively. The ${ }^{1} \mathrm{H}-\mathrm{NMR}$ spectra of the (APS-SchH), (APS-SchF), exhibit two signals at $10.70 \mathrm{ppm}$ and $10.25 \mathrm{ppm}$, which are assigned to the $-\mathrm{OH}$ and $-\mathrm{NH}$ protons, respectively. The spectra strongly suggest that even in solution the keto and enol forms remain as two dominant species in polymeric-Schiff bases. Similar keto-enol tautomerism has been previously reported in other our studies ${ }^{20}$. The
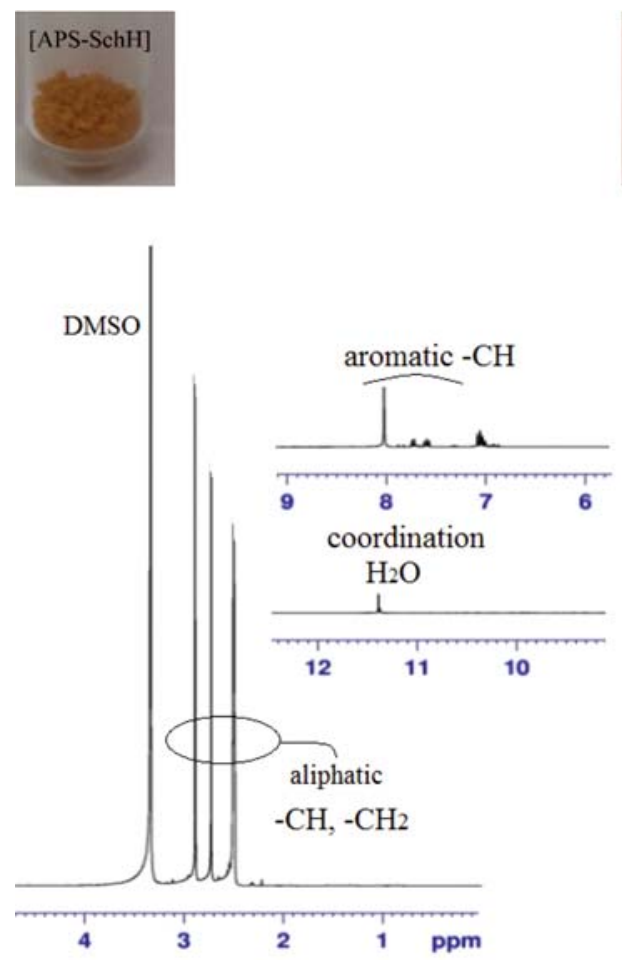

ring proton signals appear at $8.00-6.70 \mathrm{ppm}, 8.00-6.70$, 7.28-6.60 ppm and 7.20-6.61 ppm for (APS-SchH), (APS-SchF), (APS-SchCl) and (APS-SchBr), respectively. $\left[\mathrm{PS}-\mathrm{SchH}-\mathrm{Pt}^{2+}\right]$ and $\left[\mathrm{PS}-\mathrm{SchCl}-\mathrm{Pt}^{2+}\right]$ from coordination polymer-complexes showed that $-\mathrm{OH}$ protons at 11.40 ppm and $11.70 \mathrm{ppm}$ due to coordination water respectively (Table 3 and Fig. 3). At the same time, the aromatic proton moves downfield as a result of the variation in the charge density of molecule via the complex.

UV-Vis spectra of all compounds were taken in DMSO. The band observed in between 226-227 $\mathrm{nm}$ and 305 $\mathrm{nm}$ which may be considered to $\sigma \rightarrow \sigma^{*}$ and $\pi \rightarrow \pi^{*}$ transition for modified polymer, respectively. Furthermore, absorption violence showed an increase in with complexation. The lower bands in the region 324-342
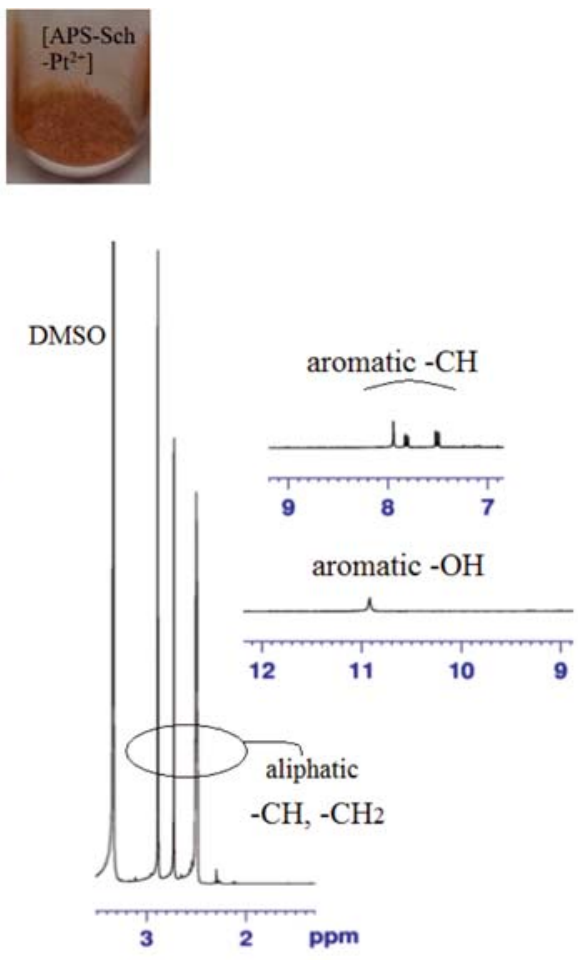

Figure 3. ${ }^{1} \mathrm{H}-\mathrm{NMR}$ spectra of (APS-SchH) and its $\mathrm{Pt}(\mathrm{II})$ coordination polymer 
Table 3. ${ }^{1} \mathrm{H}$ NMR spectra for polymer attached Schiff bases and $\mathrm{Pt}(\mathrm{II})$ complexes

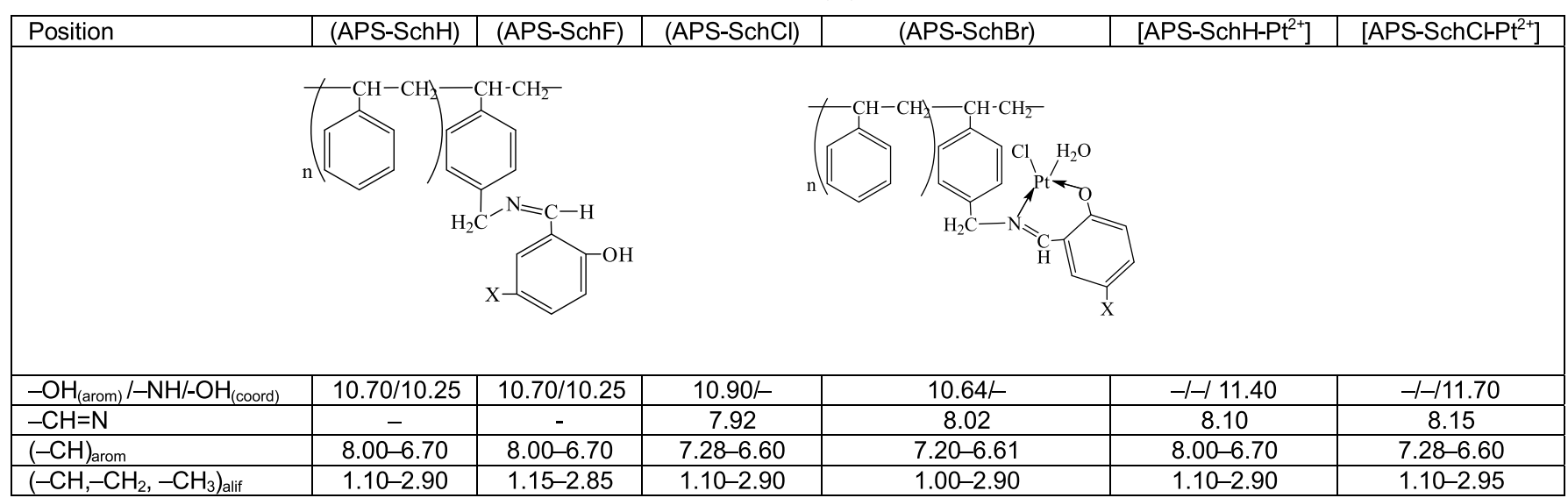

nm may be assigned to charge transfer transition which anticipated due to forbidden d-d transitions for square plane platinum(II) complexes. Furthermore, two relatively weak bands observed at $470-475 \mathrm{~nm}$ in DMSO for octahedral platinum (IV) complexes ${ }^{21}$.

\section{Scanning Electron Microscopy and EDX Analysis of Modified Platinum(II)/(IV) Complexes}

SEM images of modified polymers are shown in Table 4. SEM images of platinum coordination polymers were not markedly different from those of (APS-Sch) polymers. This image indicates that protects structure are of modified polymers from (APS-Sch) polymers. Table 4 presents the imaging and EDX spectra of synthesized (APS-SchBr) and its platinum(II) / (IV) complexes.

Table 4. SEM imaging (mag $1000 \mathrm{x})$ and EDX spectra of (APS-SchBr), (APS-SchBr-Pt $\left.{ }^{2+}\right)$ and (APS-SchBr-Pt $\left.{ }^{4+}\right)$ modified polymers

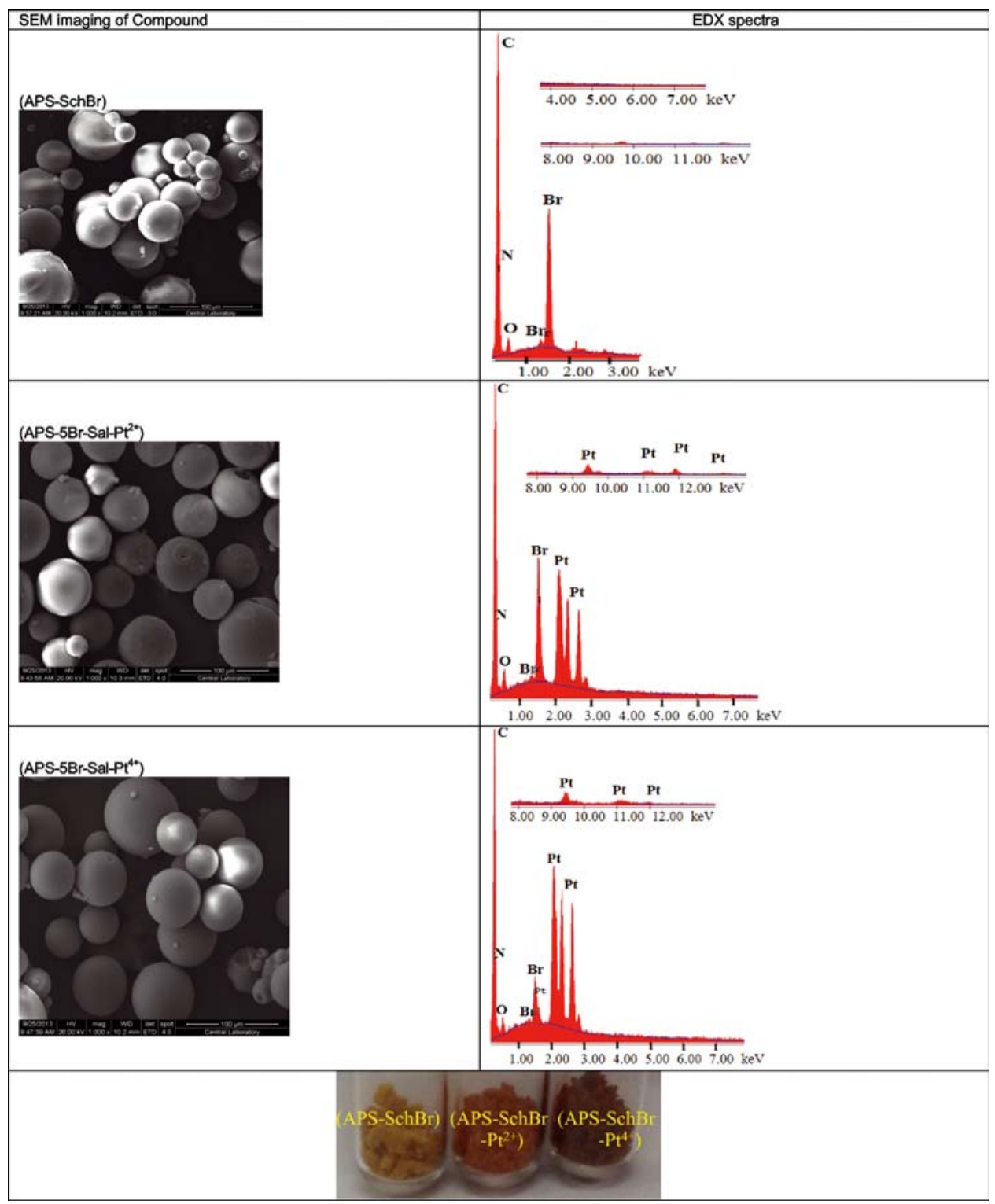


Other polymers showed similar properties. EDX analysis shows the presence of platinum ions in the prepared coordination polymer. The combined information from SEM and EDX indicate that the coordination polymer was synthesized with platinum ions.

\section{Antibacterial and Antifungal Studies}

The polymers with nano-sphere were screened for antimicrobial activity in DMF solvent as a control substance. The polymers were tested with the same concentrations in DMF solution $\left(10^{3} \mu \mathrm{M}\right)$. All the synthesized compounds and antibiotic exhibited the varying degree of inhibitory effects on the growth of different tested strains. As shown in Table 5, the results of antifungal and antibacterial screening indicated that the $\mathrm{Pt}(\mathrm{IV})$ derivatives with nano-spheres showed more activity than the other studied nano-spheres. All of the polymers with nano-sphere were active against S.aureus, C. albicans, and $B$. cereus.

As shown in Figure 1 and Figure 4, $\mathrm{Pt}(\mathrm{II})$ and $\mathrm{Pt}(\mathrm{IV})$ derivatives with nano-sphere were prepared, containing fluorine, chlorine and bromine substituents. The pharmacology test revealed that their activity order was fluorine substituent $<$ chlorine substituent $<$ bromine substituent for B. cereus, C. albicans, E. coli and L. monocytogenes 4b. As shown in Table 5, the [APS-SchH-Pt ${ }^{4+}$ ] that showed a significant activity against $C$. albicans. All of the compounds were active against $S$. aureus, $C$. albicans and B. cereus. [APS-SchH- $\mathrm{Pt}^{4+}$ ] from all coordination polymer was highly active against studied bacteria. As shown in Table 5, the [APS-SchCl] showed activity against all bacteria; however, L. monocytogenes $4 b$ did not display any

Table 5. Antimicrobial activity of polymer attached Schiff bases and $\mathrm{Pt}(\mathrm{II}) / \mathrm{Pt}(\mathrm{IV})$ complexes (0.018 g/ml) (Diameter of zone inhibition $(\mathrm{mm}))$

\begin{tabular}{|c|c|c|c|c|c|c|c|c|c|c|c|c|c|}
\hline \multicolumn{2}{|c|}{ Compound } & $\begin{array}{l}\text { [APS- } \\
\text { SchH] }\end{array}$ & $\begin{array}{l}\text { [APS- } \\
\text { SchF] }\end{array}$ & $\begin{array}{l}\text { [APS- } \\
\text { SchCl] }\end{array}$ & $\begin{array}{l}\text { [APS- } \\
\text { SchBr] }\end{array}$ & $\begin{array}{l}\text { APS- } \\
\text { SchH } \\
\left.-\mathrm{Pt}^{2+}\right]\end{array}$ & $\begin{array}{l}\text { [APS- } \\
\text { SchF } \\
\left.-\mathrm{Pt}^{2+}\right]\end{array}$ & $\begin{array}{l}{[\mathrm{APS}-} \\
\mathrm{SchCl} \\
\left.-\mathrm{Pt}^{2+}\right]\end{array}$ & $\begin{array}{l}{[\mathrm{APS}-} \\
\mathrm{SchBr} \\
\left.-\mathrm{Pt}^{2+}\right]\end{array}$ & $\begin{array}{l}\text { APS- } \\
\text { SchH } \\
\left.-\mathrm{Pt}^{4+}\right]\end{array}$ & $\begin{array}{l}\text { [APS- } \\
\text { SchF } \\
\left.-\mathrm{Pt}^{4+}\right]\end{array}$ & $\begin{array}{l}\text { [APS- } \\
\text { SchCl } \\
\left.-\mathrm{Pt}^{4+}\right]\end{array}$ & $\begin{array}{l}\text { [APS- } \\
\mathrm{SchBr} \\
\left.-\mathrm{Pt}^{4+}\right]\end{array}$ \\
\hline \multirow{7}{*}{ 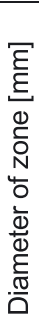 } & S. aureus & 12 & 12 & 11 & 11 & 10 & 10 & 13 & 10 & 22 & 14 & 16 & 17 \\
\hline & L. monocytogenes $4 b$ & 15 & 13 & - & 15 & 15 & 15 & 13 & 12 & 16 & 17 & 15 & 17 \\
\hline & E. coli & 13 & 16 & 15 & 15 & 17 & 15 & 14 & 12 & 20 & 11 & 13 & 12 \\
\hline & S. typhi $H$ & 12 & 11 & - & 11 & 11 & - & 11 & - & 15 & 20 & 11 & 12 \\
\hline & Br. abortus & - & - & - & 12 & 12 & 14 & 20 & 11 & 22 & - & - & 12 \\
\hline & M. luteus & 13 & 12 & - & 12 & - & - & 11 & - & 15 & 11 & - & - \\
\hline & C. albicans & 15 & 12 & 13 & 22 & 22 & 24 & 22 & 17 & 27 & 22 & 25 & 25 \\
\hline & B. cereus & 15 & 20 & 16 & 20 & 21 & 20 & 19 & 18 & 22 & 17 & 19 & 20 \\
\hline & A. fumigatus & 19 & 20 & 25 & 18 & 16 & 25 & 23 & 23 & 20 & 20 & 23 & 16 \\
\hline
\end{tabular}

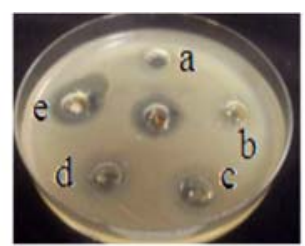

Sh.dys. typ

${ }^{\mathrm{a}}[\mathrm{APS}-\mathrm{SchCl}],{ }^{\mathrm{b}}\left[\mathrm{APS}-\mathrm{SchF}-\mathrm{Pt}^{4}{ }^{4}\right]$ [APS-SchH], ${ }^{\mathrm{A}}\left[\mathrm{APS}-\mathrm{SchH}-\mathrm{Pt}^{2+}\right.$ [AAPS-SchBr], $\left[\right.$ APS-SchF-P $\left.{ }^{2+}\right]$

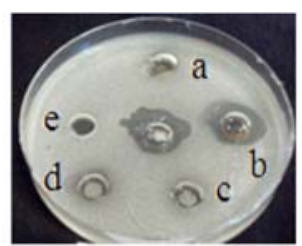

Br. abortus

a $\left[\right.$ APS-SchF], ${ }^{b}\left[\right.$ APS-SchCl-Pt $\left.{ }^{2+}\right]$ $\left[\right.$ APS-SchF-Pt $\left.{ }^{4}\right]$, d $\left[\right.$ APS-SchBr-Pt $\left.{ }^{2+}\right]$ [APS-SchF-Pt ${ }^{4}$ ], ${ }^{\mathrm{f}}\left[\mathrm{APS}-\mathrm{SchH}-\mathrm{Pt}^{4+}\right]$

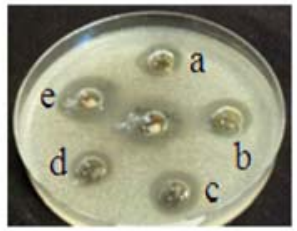

C. albicans

a[APS-SchF], b[APS-SchF-Pt $\left.{ }^{4+}\right]$

[APS-SchF-Pt] $\left.{ }^{4}\right]$ ¿ $[$ APS-SchCl]

[APS-SchBr], ${ }^{\mathrm{f}}\left[\mathrm{APS}-\mathrm{SchBr}-\mathrm{Pt}^{2+}\right]$

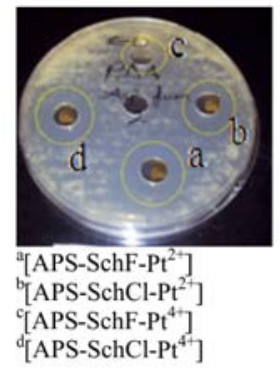

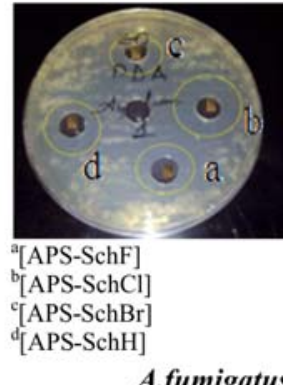

A.fumigatus

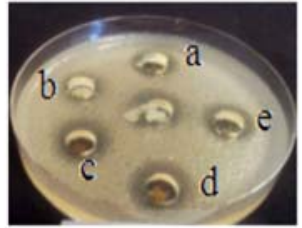

B. cereus

a[APS-SchCl], ${ }^{\mathrm{b}}$ [APS-SchH]

[APS-SchF-Pt $\left.{ }^{4}\right],{ }^{\mathrm{d}}\left[\mathrm{APS}-\mathrm{SchBr}-\mathrm{Pt}^{4}\right]$

[APS-SchBr-Pt $\left.{ }^{2}\right],{ }^{2}\left[\mathrm{APS}-\mathrm{SchCl}-\mathrm{Pt}^{4+}\right]$

Figure 4. Imaging of antimicrobial affectivities of studied some the polymers with nano-sphere 
activity against. Generally, the $\mathrm{Pt}(\mathrm{II}) / \mathrm{Pt}(\mathrm{IV})$ derivatives with nano-spheres are more potent bactericides than the ligand. This enhancement in activity may be explained on the basis of chelation theory ${ }^{20}$.

In addition, the $\mathrm{Pt}(\mathrm{IV})$ derivatives with nano-spheres are more potent bactericides than the $\mathrm{Pt}(\mathrm{IV})$ derivatives with nano-spheres. We know that bacteria needs folic acid to synthesize DNA and repair DNA. Bacteria have to make their own folic acid. $\mathrm{Pt}(\mathrm{IV})$ is kinetically more inert than $\mathrm{Pt}(\mathrm{II})$. So, $\mathrm{Pt}(\mathrm{IV})$ drugs are more stable to acidic media. Pt(IV) derivatives with nano-spheres may have been more active against studied bacteria due to its stable in acidic media ${ }^{22}$. We know that $A$. fumigatus is an emerging worldwide problem with major epidemiological and clinical implications. A. fumigatus test results of polymeric-spheres exhibited excellent activity.

\section{CONCLUSIONS}

The new Pt(II) / Pt(IV) derivatives with nanospheres compounds prepared in our study seem to have interesting biological activity. Pt(II) and Pt(IV) complexes were prepared by the template method. The structures of the prepared compound were confirmed by elemental analysis, IR, ${ }^{1} \mathrm{H}$ spectral analysis. The antibacterial and antifungal activities of the prepared compounds were evaluated showing moderate to good activities. The $\mathrm{Pt}(\mathrm{II})$ / Pt(IV) derivatives showed much better activity than ligands. We can say that this compound merits further investigation as an alternative drug. A. fumigatus test results of $\mathrm{Pt}(\mathrm{II}) / \mathrm{Pt}(\mathrm{IV})$ derivatives with nanospheres compounds are especially noteworthy.

\section{ACKNOWLEDGMENT}

This work was supported by the Gazi University Research Fund (Project number: 05/2012-53 and 05/2014-02).

\section{LITERATURE CITED}

1. Liechty, W.B., Kryscio, D.R., Slaughter, B.V. \& Peppas, N.A. (2010). Polymers for drug delivery systems. Annu. Rev. Chem. Biomol. Eng. 1, 149-173. DOI: 10.1146/annurev-chembioeng-073009-100847.

2. Hughes, G.A. (2005). Nanostructure-mediated drug delivery. Nanomed 1, 22-30. DOI: 10.1016/j.nano.2004.11.009.

3. Kohli, A.K. \& Alpar, H.O. (2004). Potential use of nanoparticles for transcutaneous vaccine delivery: effect of particle size and charge. Int. J. Pharm. 275, 13-17. DOI: 10.1016/ j.ijpharm.2003.10.038.

4. Abel, E.W., Heard P.J., Orrell, K.G., Hursthouse, M.B. \& Mazid, M.A. (1993). Halogenotrimethylplatinum (IV) complexes of 2,6-bis ( $p$-tolylthiomethyl) pyridine $\left(\mathrm{L}^{1}\right)$ : nuclear magnetic resonance studies of their solution state stereodynamics and the crystal structure of fac- $\left[\mathrm{PtBrMe}_{3} \mathrm{~L}^{1}\right]$ : J. Chem. Soc. Dalton Trans. 4, 3795-3801. DOI: 10.1039/DT9930003795.

5. Abel, E.W., Orrell, K.G., Osborne, A.G., Pain, H.M., Sik, V., Hursthouse, M.B. \& Malik, K.M.A. (1994). 2,2':6',2'-Terpyridine(terpy) acting as a fluxional bidentate ligand. Part 4.cis-[m(c6f5)(2)(terpy)] ( $\mathrm{m}=\mathrm{pd}$ or pt)-nuclear-magnetic-resonance studies of their solutiondynamics and crystal-structure of cis-[pd(c6f5)(2)(terpy)]. J. Chem. Soc., Dalton Trans. 23, 3441-3449. DOI: 10.1039/DT9940003441.

6. Yam, V.W.W., Tang, R.P.L., Wong, K.M.C. \& Cheung, K.K. (2001) Synthesis, luminescence, electrochemistry and ion-binding studies of platinum(II)terpyridyl acetylide complexes. Organomet. 20, 4476-4482. DOI: 10.1021/om010336x.
7. Yam, V.W.W., Chan, K.H.Y., Wong, K.M.C. \& Zhu, N.Y. (2005). Luminescent platinum(II) terpyridyl complexes: Effect of counter ions on solvent-induced aggregation and color changes. Eur. J. Chem. 11, 4535-4543. DOI: 10.1002/chem.200500106.

8. Pratesi, G., Perego, P., Polizzi, D., Righetti, S.C., Supino, R., Caserini, C., Manzotti, C., Giuliana, F.C., Pezzoni, G., Spinelli, S., Farrell, N. \& Zunino, F.Br. (1999). A novel charges trinuclear platinum complex effective against cisplatin-resistant tumours, hypersensitivity of p53-mutant human tumour xenografts. J. Cancer 80, 1912-1919. DOI: 10.1038/sj.bjc.6690620.

9. Kelland, L.R., Sharp, S.Y., O’Neill, C.F., Raynaud, F.I., Beale, P.J. \& Judson, I.R. (1999). Mini-review: discovery and development of platinum complexes designed to circumvent cisplatin resistance. J. Inorg Biochem. 77, 111-115. DOI: 10.1016/ S0162-0134(99)00141-5.

10. Orlandi, L., Colella, G., Bearzatto, A., Abolafio, G., Manzotti, L., Daidone, M.G. \& Zaffaroni, N. (2001). Effects of a novel trinuclear platinum complex in cisplatin-sensitive and cisplatin-resistant human ovarian cancer cell lines: interference with cell cycle progression and induction of apoptosis. Eur. J. Cancer. 37, 649-659. DOI: 10.1016/S0959-8049(00)00445-7.

11. Wheate N.J. \& Collins, J.G. (2003). Multi-nuclear platinum complexes as anti-cancer drugs. Coord. Chem. Rev. 241, 133-145. DOI: 10.1016/S0010-8545(03)00050-X.

12. Ahmedi, T.S., Wang, Z.L., Green, T.C., Henglein, A. \& El-Sayed, M.A. (1996). Shape- controlled synthesis of colloidal platinum nanoparticles. Science 272, 1924-1925. DOI: 10.1126/ science.272.5270.1924.

13. Algül, O., Ozçelik, B., Abbasoğlu, U. \& Gümüş, F. (2005). Synthesis, characterization and genotoxicity of platinum(II) complexes with substituted. Turk. J. Chem. 29, 607-615.

14. Herricks, T., Chen, J.Y., Xia, Y.N. (2004). Polyol synthesis of platinum nanoparticles: control of morphology with sodium nitrate. Nano Lett. 4, 2367-2371.

15. Asharani, P.V., Xinyi, N., Prakash, H.M. \& Valiyaveettil, S. (2010). DNA damage and p53 - mediated growth arrest in human cells treated with platinum nanoparticles. Nanomed 5, 51-64. DOI: 10.1021/n1048570a.

16. Sarı, N. \& Yüzüak, N. (2006). Synthesis, characterization of novel polymeric schiff bases their complexes. J. Inorg. Organomet. Polym. Mater. 16, 259-264. DOI: 10.1007/s10904006-9056-5.

17. Gopal, J., Hasan, N., Manikandan, M. \& Wu, H.F. (2013). Bacterial toxicity/compatibility of platinum nanospheres, nanocuboids and nanoflower. Sci. Rep. 3, 1260. DOI: 10.1038/ srep01260.

18. Nartop, D. \& Sarı, N. (2012). Novel Poly(styrene) attached Schiff Bases for uptake Mn(II) and Ni(II)ions and as antimicrobial agent against micrococcus luteus. J. Inorg. Organomet. Polym. 22, 772-779. DOI: 10.1007/s10904-011-9634-z.

19. Sarı, N., Pişkin, N., Öğütcü, H. \& Kurnaz, N. (2013). Spectroscopic characterization of novel D-aminoacid-Schiff bases and their $\mathrm{Cr}(\mathrm{III})$ and $\mathrm{Ni}(\mathrm{II})$ complexes as antimicrobial agents. Med. Chem. Res. 22, 580-587. DOI: 10.1007/s00044012-0039-5.

20. Bozkır, E., Sari, N. \& Öğütçü, H. (2012). Polystyrene containing carbinolamine/azomethine potentially useful as antimicrobial agent synthesis and biological evaluation. $J$. Inorg. Organomet. Polym. Mater. 22, 1146-1155. DOI: 10.1007/ s10904-012-9697-5.

21. Swihart, D.L. \& Mason, W.R. (1970). Electronic spectra of octahedral platinum (IV) complexes. Inorg. Chem. 9, 1749-1757. DOI: 10.1021/ic50089a029.

22. Keland, L.R., Mistry, P., Abel, G., Loh, S.Y., O'Neil, C.F., Murer, B.A. \& Harrap, K.R. (1992). Mechanism-related circumvention of acquired cis- diamminedichloroplatinum (II) resistance using two pairs of human ovarian carcinoma cell lines by ammine/amine platinum(IV) dicarboxylates. Cancer Res. 52, 3857-3864. 